\title{
Development of a Toxicological Gene Array and Quantitative Assessment of This Technology ${ }^{1}$
}

\author{
Matthew Bartosiewicz, ${ }^{* 2}$ Mary Trounstine, $\dagger^{, 3}$ David Barker,$\dagger$ \\ Richard J ohnston, $\dagger^{4}$ and Alan Buckpitt* \\ *Department of Molecular Biosciences, School of Veterinary Medicine, University of California, \\ Davis, California 95616; and †Molecular Dynamics, Sunnyvale, California 94086-4520
}

Received September 9, 1999, and in revised form December 20, 1999

High-density arrays of DNA bound to solid substrates offer a powerful approach to identifying changes in gene expression in response to toxicants. While DNA arrays have been used to explore qualitative changes in gene regulation, less attention has focused on the quantitative aspects of this technology. Arrays containing expressed sequence tags for xenobiotic metabolizing enzymes, proteins associated with glutathione regulation, DNA repair enzymes, heat shock proteins, and housekeeping genes were used to examine gene expression in response to $\beta$-naphthoflavone ( $\beta$-NF). Upregulation of cytochrome P450lal (Cypla1) and $1 \mathrm{a} 2$ in mouse liver was maximal $8 \mathrm{~h}$ after $\beta$-NF administration. Significant upregulation of Cypla2 was noted at $\beta$-NF doses as low as 0.62 and 1.2 $\mathrm{mg} / \mathrm{kg}$ when gene expression was measured by $\mathrm{mi}-$ croarray or Northern blotting, respectively. Maximal Cypla2 induction is 5-fold by Northern analysis and 10-fold by microarray. Induction of Cyplal was 15and 20-fold by Northern and microarray analysis, respectively. The coefficient of variation for spot to spot and slide to slide comparisons was < 15\%; this variability was smaller than interanimal variability (18-60\%). Comparison of mRNA expression in control animals indicated that there are differences in labeling/detection associated with Cy3/Cy5 dyes; accordingly, experiments must include methods for establishing baseline signals for all genes. We conclude that the dynamic

\footnotetext{
${ }^{1}$ This research was supported by NIEHS P42 04699 and R01ES09681. U.C. Davis is an NIEHS Center in Environmental Health (ES 05707) and the use of core facilities to conduct this work is gratefully acknowledged. M.B. has been supported by a fellowship from the Toxic Substances Research and Training Program, University of California.

${ }^{2}$ To whom correspondence should be addressed.

${ }^{3}$ Present address: Corning, Inc., Corning, NY 14830.

${ }^{4}$ Present address: Incyte Pharmaceuticals, Palo Alto, CA.
}

range and sensitivity of DNA microarrays on glass slides is comparable to Northern blotting analysis and that variability of the data introduced during spotting and hybridization is less than the interanimal variability. $\odot 2000$ Academic Press

Key Words: DNA arrays; $\beta$-napthoflavone; gene expression.

High throughput techniques for spotting hundreds and even thousands of DNAs on either glass slides or filters offer the ability to detect changes in gene expression in response to a variety of conditions including diseases such as cancer and arthritis (1-3) and potentially to injury associated with exposure to toxic substances. Considerable effort has focused on the development of techniques for printing glass slides with DNAs at high density, for dual fluorescent dye labeling, and for measurement of the fluorescent images obtained from these arrays $(4,5)$. Although many of the reported studies have utilized tissues or cell lines, little work has examined issues using whole animals. A genome-wide understanding of the underlying reactions of cells to injury as well as the processes associated with repair would provide important information about some of the underlying cellular changes that occur in response to stressors. Additionally, it is possible that this technology could be used not only as a tool for exposure screening but that the pattern of gene expression in response to different classes of toxicants will be sufficiently unique to allow tentative identification of the toxic agent. Indeed, this issue is being addressed in several laboratories including ours $(6,7)$.

Although microarrays may provide methods for conducting such studies, there is a need to verify the quantitative aspects of the technology in the whole animal. Several studies have examined the compara- 
tive aspects of microarrays with standard methodologies including Northern/dot blotting (8) and quantitative PCR (9) and have demonstrated that expression of even rare gene transcripts (less than $0.1 \%$ ) can be measured quantitatively (10). There has been little discussion, however, regarding the ability of arrays to measure small changes in gene expression and whether these approaches have dynamic range similar to standard approaches such as Northern blot analysis. In addition, the microarray strategy used in most laboratories involves spotting thousands of genes per slide and little attention has focused on the variability associated with dye labeling, spotting/reading or slide preparation.

This report describes work that addresses some of the quantitative issues associated with the use of DNA arrays as tools for assessing gene regulation. A simple toxicology chip which contains 148 expressed sequence tags $(\mathrm{ESTS})^{5}$ for genes coding for both phase I and phase II metabolizing enzymes, DNA repair enzymes, stress proteins, cytokines, and housekeeping genes has been developed to examine the sensitivity and dynamic range of the arrays. (A complete list of ESTs may be obtained at http://www. vetmed. ucdavis.edu/vmb/ m.biosciences.html). Each unique EST was spotted eight times, producing an array of 1184 spots. These arrays were then used as targets to assess mRNA levels from control mice and mice treated with a full range of doses of $\beta$-naphthoflavone $(\beta-N F)$. This study demonstrates that the sensitivity of microarrays in detecting upregulation of genes is equal to or better than that of Northern blots. Moreover, animal-to-animal variability is generally greater than variability associated with the spotting, hybridization, or data acquisition associated with gene chips. We conclude that gene chips are equally sensitive and have similar dynamic range to more classical techniques for monitoring gene expression.

\section{MATERIALS AND METHODS}

Animals. Male Swiss Webster mice (20-25 g) were obtained from Charles River Breeding Labs and were housed in animal care facilities at the University of California-Davis, which are accredited by the American Association of Laboratory Animal Care. Mice were provided food and water ad libitum and were housed in HEPAfiltered racks for at least 1 week before use.

Animal treatment and isolation of mRNA. Mice (4-5/group) were treated intraperitoneally (i.p.) with doses of $\beta$-napthoflavone (Sigma Chemical Co., St. Louis, MO) varying from 0.15 to $80 \mathrm{mg} / \mathrm{kg}$ dissolved in corn oil $(10 \mathrm{ml} / \mathrm{kg})$. Controls received corn oil only. At time points specified in the figure legends, mice were euthanized with an overdose of pentobarbital. The liver was removed, rinsed in isotonic

\footnotetext{
${ }^{5}$ Abbreviations used: EST, expressed sequence tag; $\beta \mathrm{NF}, \beta$-naphthoflavone; DEPC, diethyl pyrocarbonate; DTT, dithiothreitol; Cyplal, cytochrome P-450 1a1; SSC, standard sodium citrate; SDS, sodium dodecyl sulfate; RFU, relative fluorescent unit.
}

saline, weighed, homogenized immediately in Trizol (GIBCO BRL, Bethesda, MD), and RNA isolated as described by Chomczynski and Sacchi (11). Total RNA pellets were stored at $-20^{\circ} \mathrm{C}$ in $70 \%$ ethanol. Total RNA in $70 \%$ ethanol was pelleted by centrifugation, the supernatant was removed and pellets were air dried and resuspended in $200 \mu \mathrm{l}$ of diethyl pyrocarbonate (DEPC)-treated water. DNase solution (20 mM MgCl 2,2 mM DTT, 700 units/ml RNase-free DNase, and 400 units/ml RNasin (Ambion, Austin, TX)) was added and the mixture was incubated for $30 \mathrm{~min}$ at $37^{\circ} \mathrm{C}$. The reaction mixture was then extracted with phenol/chloroform and RNA precipitated with ethanol. DNase-treated total RNA $(500 \mu \mathrm{g})$ was used to isolate mRNA using oligo(dT) resin (Qiagen, Valencia, CA) following the manufacturer's instructions.

EST fragments and amplification. Approximately 150 unique genes involved in phase I and phase II metabolism, heat shock, DNA repair, inflammation, transcription, and housekeeping were ordered as expressed sequence tags (corresponding to the $3^{\prime}$ region of the respective genes) from the I mage Consortium CDNA mouse libraries through suppliers (Research Genetics, Huntsville, AL, or ATCC, Bethesda, MD). BLAST was used to determine which EST fragments, corresponding to desired genes, contained the least homology to other known genes. For those ESTs which contained areas of high homology (i.e., cytochrome P-450 la1 (Cypla1) and Cypla2 ) PCR primers were designed to amplify unique regions for spotting on slides.

cDNA clones (bacterial stab or freeze dried) were grown in LB media containing $50 \mu \mathrm{g} / \mathrm{ml}$ ampicillin (or other antibiotic required for specific clones) overnight at $37^{\circ} \mathrm{C}$ with shaking. Plasmid DNA was isolated from the bacterial cultures using a plasmid purification kit (Qiagen) according to the manufacturer's instructions. The ESTs contained within the plasmid were PCR amplified $\left(1 \times 94^{\circ} \mathrm{C}\right.$ for 5 $\min , 35 \times 94^{\circ} \mathrm{C}$ for $30 \mathrm{~s}, 52^{\circ} \mathrm{C}$ for $30 \mathrm{~s}, 72^{\circ} \mathrm{C}$ for $90 \mathrm{~s}, 1 \times 72^{\circ} \mathrm{C}$ for 5 min, and $1 \times 4^{\circ} \mathrm{C}$ hold) using either T3 or T7 primers, M 13 forward and reverse primers (GIBCO), or gene-specific primers in $100 \mu \mathrm{l}$ reactions. An aliquot of these $P C R$ reactions were electrophoresed on $1.2 \%$ agarose gels to determine size and purity. Some of the PCR products contained more than a single fragment. For these products, new PCR primers were constructed for the EST of interest. These PCR fragments were then confirmed by size on agarose gels. The sequence of those ESTs which were PCR amplified and which contained a single product (by gel electrophoresis) was confirmed using a Molecular Dynamics Megabace DNA sequencer according to standard protocols. Final PCR products varied in size from approximately 500 bp to 1200 bp and were purified by binding to "Qiaquick" columns (Qiagen). PCR products were eluted in $30 \mu \mathrm{l}$ of $10 \mathrm{mM}$ Tris, $\mathrm{pH}$ 8.5, and the concentrations were determined by absorbance at $260 \mathrm{~nm}$.

Spotting DNA arrays. Each purified PCR product (10 $\mu$ l at concentrations $>200 \mathrm{ng} / \mu \mathrm{l}$ ) was mixed with $10 \mu \mathrm{l}$ of $8 \mathrm{M} \mathrm{NaSCN}$ in 96-well plates and the DNA was spotted using the Molecular Dynamics Microarray Spotter Gen II, onto slides treated by vapor deposition of 3-aminopropyltrimethoxy silane. Each gene was spotted in eight separate quadrants of the slide (Fig. 1). The slides were baked at $80^{\circ} \mathrm{C}$ for $2 \mathrm{~h}$ and stored at room temperature in a desiccator until use. Prior to hybridization, the slides were washed in isopropanol for $10 \mathrm{~min}$ and then boiled in water for $5 \mathrm{~min}$.

Preparation of CDNA probes labeled with Cy3 or Cy5. Су3- and Cy5-labeled probes were prepared using $1 \mu \mathrm{g}$ mRNA from control or treated animals, respectively. mRNA was added to $2 \mu \mathrm{l}$ of oligo(dT) primer $(0.5 \mu \mathrm{g} / \mu \mathrm{l})(\mathrm{GIBCO})$, DEPC water was used to bring the volume to $11 \mu \mathrm{l}$, and the mixture was incubated at $70^{\circ} \mathrm{C}$ for $10 \mathrm{~min}$ and placed on ice. A reaction mixture consisting of $\mathrm{mRNA}$, firststrand buffer (GIBCO), DTT (0.1 M), dNTP (-dCTP) (2 mM), $1 \mathrm{mM}$ CTP , 1 mM Cy3-dCTP (control mRNA) or Cy5-dCTP ( $\beta$-NF-treated mRNA) (Amersham Life Sciences, Piscataway, NJ ), RNasin, and Superscript II reverse transcriptase enzyme (GIBCO) in a total volume of $20 \mu \mathrm{l}$ was incubated in the dark for $2 \mathrm{~h}$ at $42^{\circ} \mathrm{C}$ and placed on ice. RNase H (GIBCO) was added to the labeled probe and the 

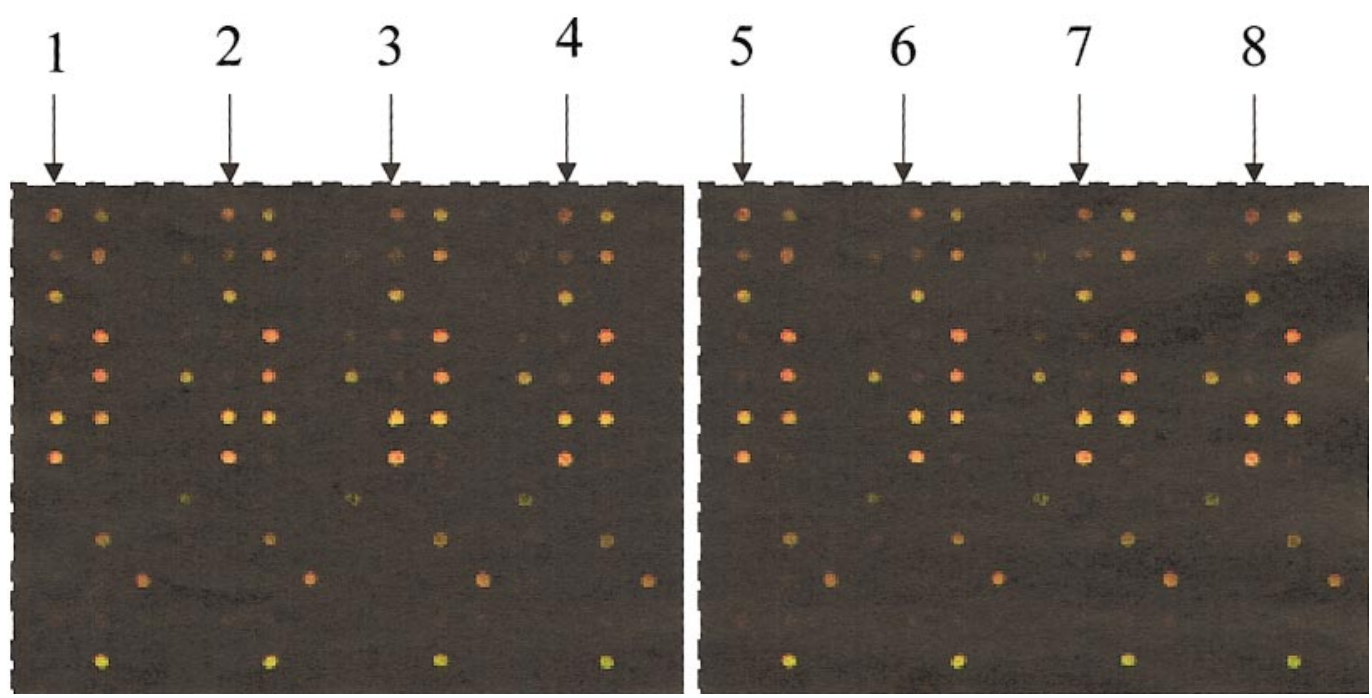

FIG. 1. Representative array showing results from a single pen set on the Gen II spotter. Duplicate spots (1 and 5) were arrayed on each half of the glass slide, pens were rinsed, and additional sample was arrayed in duplicate (spots 2 and 6 ). Spots 3 and 7 and 4 and 8 are additional duplicate spots of the same sample.

mixture was incubated in the dark for $30 \mathrm{~min}$ at $37^{\circ} \mathrm{C}$ to degrade the template RNA. Single-stranded CDNA probes were purified using a PCR purification kit (Qiagen). Columns were washed twice with 500 $\mu \mathrm{l}$ of buffer and the labeled probes were eluted with $2 \times 30 \mu$ l elution buffer according to the manufacturer's protocol. The absorbance of each probe preparation was determined at $260 \mathrm{~nm}$ and either $550 \mathrm{~nm}$ (Cy3) or $650 \mathrm{~nm}$ (Cy5). The total dye content (pmoles), amount of probe (ng), and specific activity (No. of Cy molecules incorporated/No. of bases) were calculated. Probe mixtures were evaporated in a vacuum centrifuge.

Hybridization. Hybridization solution containing $50 \%$ formamide, $5 \times$ SSC, $0.1 \%$ SDS (final volume) was filtered though a $0.1 \mu \mathrm{m}$ filter. Poly A (Amersham Life Sciences) and mouse Cot DNA (GIBCO) were added to the hybridization solution at a final concentration of 16 and $40 \mathrm{ng} / \mu \mathrm{l}$, respectively. Probes were resuspended in $11 \mu \mathrm{l}$ hybridization solution. Cy3 (control) and Cy5 (treated) probes were matched based on total dye content (pmoles) and mixed. The mixed probes were boiled for $5 \mathrm{~min}$ and then centrifuged briefly. The probe mixture $(22 \mu \mathrm{l})$ was placed on a previously prepared array and a coverslip was slowly placed over the solution, avoiding air bubbles. The slides were hybridized overnight at $42^{\circ} \mathrm{C}$ in a humid chamber. Following hybridization, slides were placed in a wash solution ( $2 \times$ SSC, $0.1 \%$ SDS) for $5 \mathrm{~min}$ at $37^{\circ} \mathrm{C}$ with gentle shaking. Coverslips floated off the slides during this initial wash. Slides were then washed once in $0.1 \times$ SSC, $0.1 \%$ SDS at room temperature for $5 \mathrm{~min}$ and twice in $0.1 \times \mathrm{SSC}$ at room temperature for a total of $5 \mathrm{~min}$. The slides were then rinsed briefly in water and dried with a gentle stream of nitrogen.

Analysis of fluorescence spots. Slides, prepared as described above, were scanned on the Molecular Dynamics MicroArray Scanner (12). Both Cy3 and Cy5 channels were scanned at a photomultiplier tube setting of $750 \mathrm{~V}$. Analysis of the data sets was performed using ArrayVision Software (I maging Research, St. Catherines, Ontario, Canada). The fluorescence intensity of each spot was calculated using local median background subtraction. The relative fluorescent units (RFUs) were then normalized to the median signal of probe (Cy3 and Cy5) for that slide. The change in gene expression for each spot was calculated as $R F U_{\text {treated }} / R U_{\text {control }}$. This value was then compared to its duplicate (that is $R F U_{\text {treated }} / R F U_{\text {control }}$ for spot 1 versus spot 5, Fig. 1). If the ratio of the value for these two spots was between 0.67 and 1.5 the spot and duplicate were accepted and an average value of induction was calculated. If the value was not within $50 \%$ of its replicate, the spot was rejected from the set. This criterion tended to exclude those spots that were contaminated with dust or those slides that had variable and high backgrounds. Of the values obtained during this work, $10-20 \%$ were rejected using these criteria. The data on those genes upregulated by $\beta$-NF treatment are presented as the mean $\pm \mathrm{SD}$, percentage of the control. For those signals which were apparently downregulated, a different approach was necessary since repression of signal has less dynamic range than upregulation of signal. Specifically, a repressed signal can vary from 0 to $100 \%$ of control, whereas induction of signal can be many fold higher. Accordingly, all data, where signals associated with the mRNA isolated from treated liver were lower than controls, were converted to natural logs, means and 95\% confidence intervals were calculated, and these data were reconverted to an arithmatic scale for graphical presentation. Data are presented as means with $95 \%$ confidence intervals. Significant differences between control and treatment doses were determined using a two-tailed t test. In some cases a Mann-Whitney Rank Sum test was performed. P values $<0.05$ were considered statistically significant.

Northern blotting. Selected PCR products arrayed onto the glass slides (Cyp 1a1, Cypla2, and GAPDH) were used as probes in the Northern hybridizations. Total RNA from individual mouse livers was run on a Northern Max-Gly gel (Ambion) and transferred to nylon membrane. PCR probes were produced using the BrightStar Psoralen-Biotin labeling kit (Ambion) following the manufacturer's instructions. Hybridization and washing procedures also were carried out following Ambion's protocol. The membrane was then treated for chemiluminescence detection using the BrightStar Biodetect kit (Ambion). The membrane was exposed to film (Fuji) for various times. The images on the film were scanned on a Molecular Dynamics Personal Densitometer and analyzed in I mageQuant (Molecular Dynamics).

\section{RESULTS}

Time course upregulation of Cypla1 and Cypla2 in $\beta$-NF-treated mice. $\beta$-NF upregulates a number of genes including Cyplal and Cypla2. To determine the time course of upregulation of these two genes, mice 


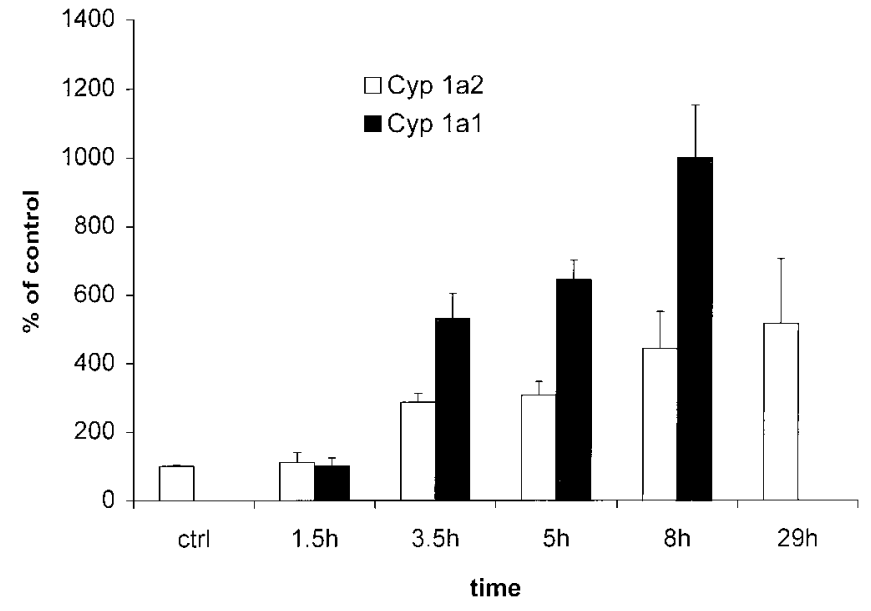

FIG. 2. Time course expression of Cyplal and Cypla2 in livers from mice treated with $80 \mathrm{mg} / \mathrm{kg} \beta-\mathrm{NF}$. Expression was analyzed by Northern blotting and normalized to GAPDH. Data represents the mean \pm SD for three animals at each time point. No signal was detected for Cyplal in control animals and accordingly the signal at all time points was compared to that observed at $1.5 \mathrm{~h}$.

were treated intraperitoneally with doses of $80 \mathrm{mg} / \mathrm{kg}$ $\beta-\mathrm{NF}$ and were euthanized at times ranging from 1.5 to $29 \mathrm{~h}$ later. Total RNA was extracted from the liver and used for Northern blotting experiments. All values were normalized to GAPDH. Since no signal was detected for Cyplal in control animals, the degree of induction of this gene was calculated based on increases in signal over that at $1.5 \mathrm{~h}$, the earliest time at which signal was detected. The induction of both Cyplal and Cypla2 increased with time and was maximal at $8 \mathrm{~h} \mathrm{(Fig.} \mathrm{2).} \mathrm{The} \mathrm{maximal} \mathrm{induction} \mathrm{of} \mathrm{Cyplal}$ and Cypla2 was 1000 and $500 \%$ of control, respectively. The signal for Cyplal decreased to control values at $29 \mathrm{~h}$, whereas the signal for Cypla2 remained constant to this time point. Accordingly, the 8-h time point was selected for further studies to examine issues associated with the use of microarrays as quantitative tools for assessing gene expression.

Comparison of induction of Cypla1 and Cypla2 as assessed by microarrays and Northern blotting analysis: Dose response Groups of four to five mice were treated intraperitoneally with $\beta$-NF at doses varying from 0.1 to $80 \mathrm{mg} / \mathrm{kg}$; total RNA was extracted from livers of mice killed $8 \mathrm{~h}$ after treatment for comparison of gene expression by Northern blotting and microarray. The pattern of induction for Cypla2, as assessed by both Northern blots and microarrays, was similar (Fig. 3). Significant induction was noted at the 1.2 $\mathrm{mg} / \mathrm{kg} \beta$-NF dose in the Northern blotting experiments (Fig. 3B) and at $0.62 \mathrm{mg} / \mathrm{kg}$ when signals were analyzed on microarrays (Fig. 3A). The increase in signal for Cypla2 at $80 \mathrm{mg} / \mathrm{kg}$ compared to control was approximately 7.5 - and 12 -fold ( 750 and $1200 \%$ control) when assessed by Northern blotting or microarray analysis, respectively (Fig. 3). The signal for Cyplal was not detectable by Northern blotting with chemiluminescence detection at doses of $\beta$-NF bel ow $2.5 \mathrm{mg} / \mathrm{kg}$. Significant increase in signal, over the $2.5 \mathrm{mg} / \mathrm{kg}$ dose, was noted at doses of $5 \mathrm{mg} / \mathrm{kg}$ and above (Fig. 4A). When signals were analyzed on microarrays, small but detectable fluorescence signals for Cyplal were noted in both the Cy5 and the Cy3 channels using mRNA from control or animals treated with $0.15 \mathrm{mg} / \mathrm{kg} \beta$-NF . Significant increases in the fluorescence intensity for Cy5/Cy3-labeled RNA above control were observed for Cyplal at doses $\geq 2.5 \mathrm{mg} / \mathrm{kg} \beta$-NF (Fig. 4B). As was the case with Cypla2, the dynamic range of the signal for Cyplal (in this case the ratio of the signal at $80 \mathrm{mg} / \mathrm{kg}$ $\beta$-NF to that at $2.5 \mathrm{mg} / \mathrm{kg}$ ) was similar with Northern blotting analysis (15-fold increase) and microarrays (20-fold increase) (Fig. 4). The variability in signal for Cypla2 was similar with microarray analysis (31\%
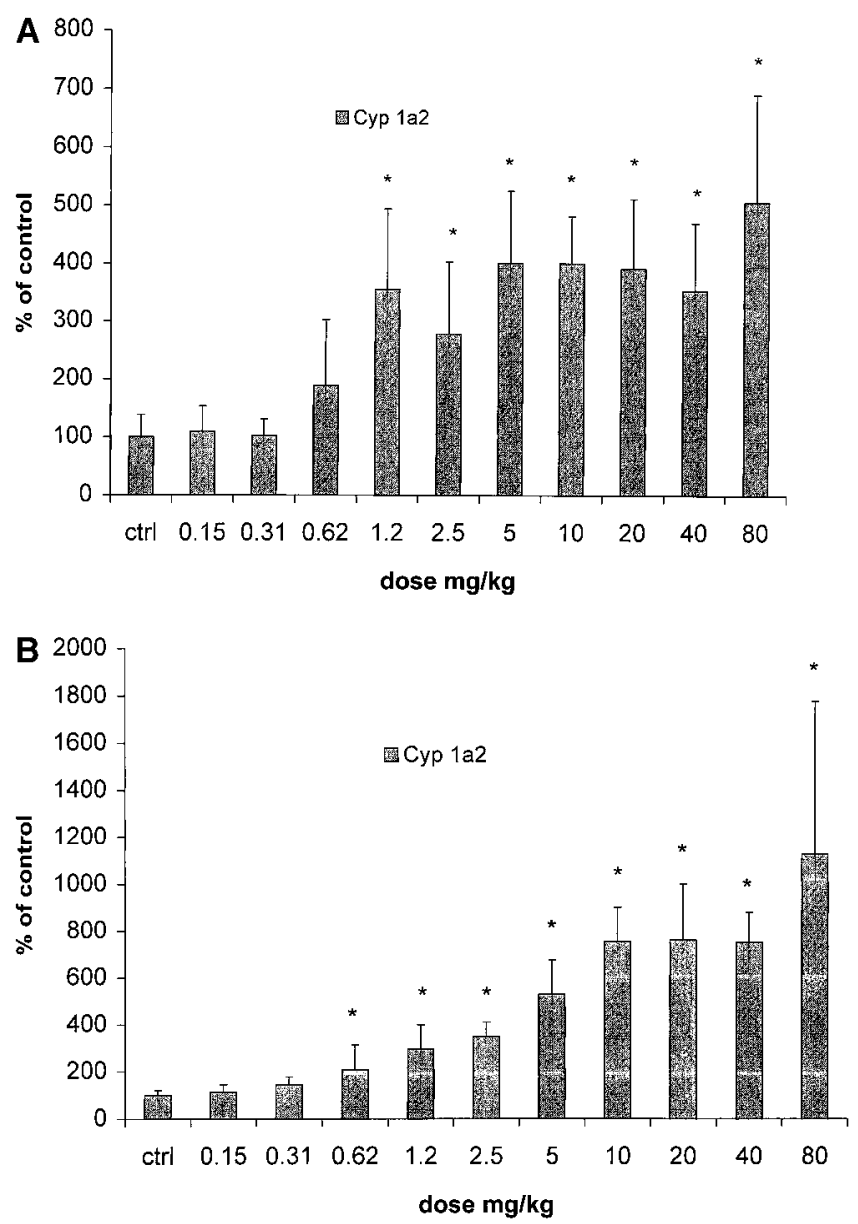

FIG. 3. Cypla2 gene expression in livers of mice treated with varying doses of $\beta$-NF. In (A) expression was analyzed by Northern blotting and in (B) by the use of microarray. Values represent the mean \pm SD for four to five animals at each dose. This study shows good correspondence in mRNA levels assessed by Northern blotting and by microarray. *, Significant difference from control $\mathrm{P}<0.05$. 

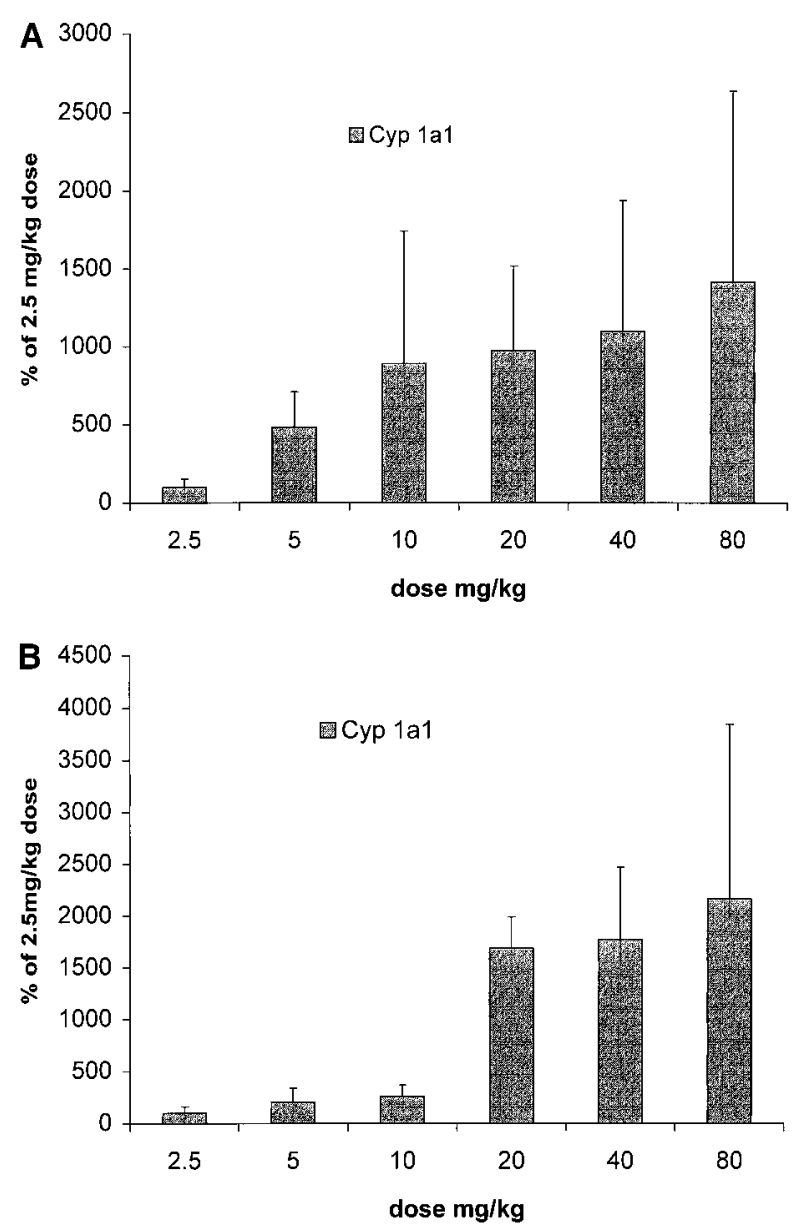

FIG. 4. Cyplal gene expression in livers of mice treated with varying doses of $\beta$-NF. Expression was assessed by Northern blotting (A) and by microarray (B). Signal was not detected in Northern blots at doses of $\beta$-NF under $2.5 \mathrm{mg} / \mathrm{kg}$; thus all signals were normalized using the $2.5 \mathrm{mg} / \mathrm{kg}$ dose as $100 \%$. Values are the mean \pm SD for livers from four to five animals at each dose.

coefficient of variation for all doses) to that observed with N orthern blotting (37\% coefficient of variation for all doses).

Induction repression of other genes by $\beta$-NF. Metallothioneins I and II appeared, by microarray analysis, to be induced at some doses of $\beta$-NF (up to sevenfold) but to be repressed at other doses to $30 \%$ of the Cy3 controls (data not shown). The lack of a consistent dose-response relationship for metallothionein gene expression suggested that there are some genes which may vary considerably and that, at least in examining changes in gene expression in response to xenobiotics, dose-response relationships need to be clearly established. Other genes, such as integrin alpha V (Fig. 5) were apparently repressed in comparison with corn oil-treated controls at all doses of $\beta$-NF tested. The finding that repression of integrin alpha $V$ was not dependent on dose of $\beta$-NF suggested that the differ- ences in signal for treated vs control might be related to bias in dye labeling or in differences associated with detection of the two fluorescent labels. This possibility is supported by the finding that comparison of Cy3- and Cy5-labeled control yiel ded ratios of Cy5/Cy3 similar to those noted between Cy5-labeled cDNA from treated animals and Cy3-labeled cDNA from control. Further support for the view that bias in either dye labeling or reading intensity of the fluorescent signals for the dyes accounted for the apparent low Cy5/Cy3 signal ratios for some genes was obtained in additional studies where dye labels were reversed-namely mRNA from control animals was labeled with Cy5, while mRNA from treated animals was Cy3 dye labeled. This was the case with integrin alpha $\mathrm{V}$ where use of Cy3 and Cy5 to label-treated and control cDNA, respectively, appeared to demonstrate that this gene is upregulated by $\beta$-NF (data not shown). To control for dye/detection bias, separate controls were labeled with both Cy5 and Cy3 to establish a baseline in all experiments and this baseline was used to determine significant induction or repression of gene expression in response to $\beta$-NF treatment.

Alterations in the expression of "housekeeping" genes. To determine whether there are potential changes in expression of housekeeping genes (GAPDH (Fig. 6A) and actin (Fig. 6B)), fluorescence ratios for Cy5/Cy3 dyes were monitored in control vs $\beta$-NFtreated animals. The signals for GAPDH varied

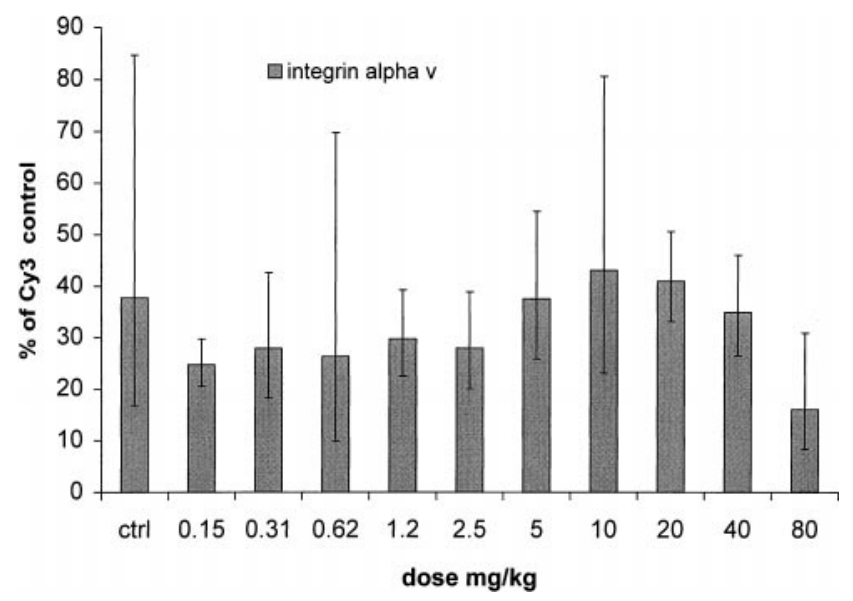

FIG. 5. Integrin alpha $V$ gene expression in livers of mice treated with varying doses of $\beta-\mathrm{NF}$. Because there is repression at all doses of $\beta$-NF all values are presented as a percentage of the Cy3 control with $95 \%$ confidence intervals indicated by the error bars. Four to five animals were used per dose and three animals were utilized to establish control vs control values. Note that the ratio of Cy5/Cy3 was lower for integrin alpha $\mathrm{V}$ than the control at all doses tested. Differences in labeling reactions or in the detection of Cy3 and Cy5 for control and treated samples may account for the apparent downregulation. This is supported by the finding that comparison of control vs control shows a similar level of repression. Values are the mean $\pm \mathrm{SD}$. 

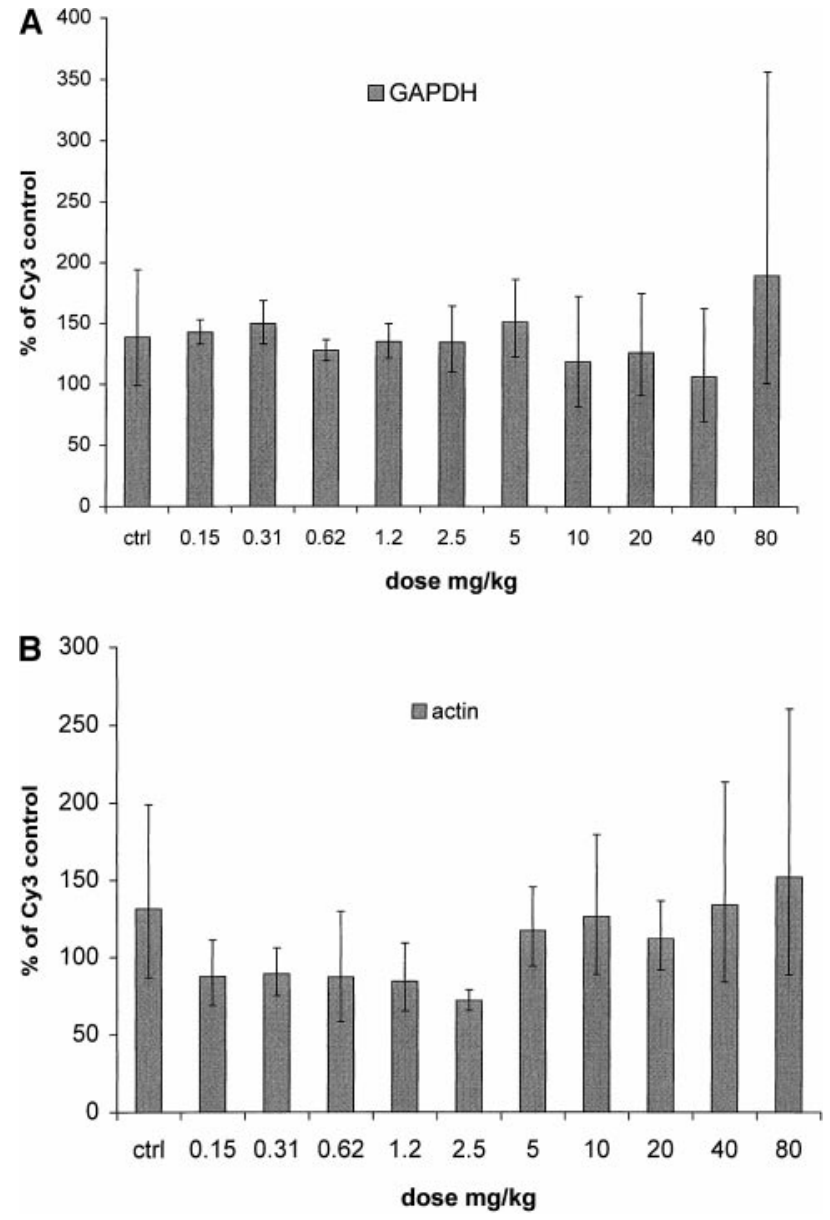

FIG. 6. Levels of expression of GAPDH (A) and actin (B) (housekeeping genes) in livers of mice treated with varying doses of $\beta$-NF. Values are mean with $95 \%$ confidence intervals from four to five separate animals. Note the consistency in gene expression across this dose range.

slightly over the dose range tested but generally were within 100-150\% of control values (Fig. 6A). Similarly, signals with actin remain consistent throughout the doses of $\beta$-NF tested (70 to $150 \%$ of the signal observed in control animals) but there was more variability at the $80 \mathrm{mg} / \mathrm{kg}$ dose (75 to $250 \%$ of the ratio observed with corn oil controls) (Fig. 6B).

Sources of variability in microarray analysis. All ESTs were spotted eight times/slide on five different slides to explore slide-to-slide variability. Five separate $\mathrm{Cy} 5$ and $\mathrm{Cy} 3$ reactions were conducted using liver RNA from control mice or mice treated with $5 \mathrm{mg} / \mathrm{kg}$ $\beta$-NF. Cy5 and Cy3 reactions were pooled and equal volumes were used as probes for analysis. All slides were from the same batch of slides. The relative fluorescence for treated (Cy5) to control (Сy3) was then compared for Cypla2. The coefficient of variation for Cy5/Cy3 fluorescence signal was 14\% (open bar, Fig. 7) indicating good consistency of data obtained from dif- ferent slides. The spot-to-spot variability, calculated from the variance of Cy 5/Cy 3 ratios for eight spots on each slide at the full range of doses of $\beta$-NF was $8-18 \%$ (dark bars, Fig. 7). Much of the variability in signal can be attributed to animal-to-animal differences which varied from $18 \%$ to nearly $60 \%$ (cross hatch, Fig. 7 ).

\section{DISCUSSION}

The design of the majority of microarray studies has focused on illustrating the ability of arrays to monitor the expression levels for thousands of genes simultaneously. Although this approach has been very informative and has demonstrated that the arrays have great potential for exploring the roles of hundreds of genes and of identifying novel genes associated with various disease processes, less attention has been focused on the quantitative aspects of these approaches. I ndeed these issues have not been fully explored nor are the limitations of the use of DNA arrays well-established. Our primary goal has been to understand the potential limitations of this technology prior to the development of chips which are useful in both environmental monitoring and in exploring changes in gene regulation in response to toxic substance exposure.

While the goal of many of the published studies on DNA arrays has been to spot a maximum number of unique genes, our results indicate sufficient variability in spot-to-spot and slide-to-slide replicates to suggest that multiple spots of the same gene on at least duplicate slides with the more focused battery of genes on the slide may be a better approach for trying to im-

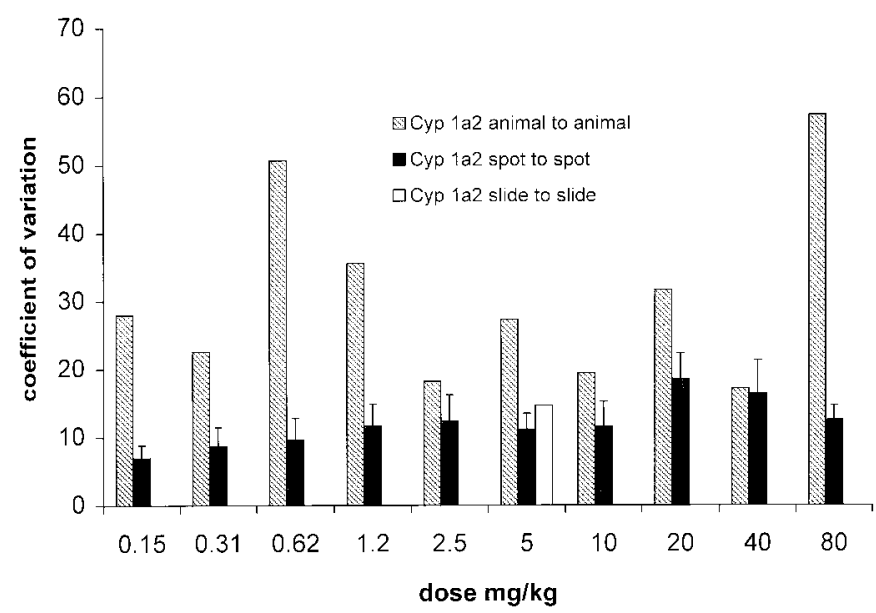

FIG. 7. Sources of variation in microarray analysis. Cross hatch represent the coefficient of variation for four to five animals at each dose of $\beta$-NF. Dark gray bars represent the coefficient of variation for values obtained from eight spots/slide and the open bar at $5 \mathrm{mg} / \mathrm{kg}$ represents the variation of data obtained from five separate slides from a pool of control and treated mouse liver RNA. Values are the mean $\pm \mathrm{SD}$. 
prove the ability of this technology to assess moderate changes in gene expression. This is readily apparent from the current work where we have shown that there is approximately a $10-20 \%$ variability in spots and that replicate slides yield data with an overall coefficient of variation of $14 \%$. We expect that, as the techniques for slide preparation improve, the variation between slides will decrease and that the number of data points that will need to be excluded because the two spot values did not fall within the 0.67 to 1.5 ratio will decrease as well. We note the need for very clean environments in that the presence of dust on the slides resulted in a large increase in variability and a significant increase in the number of duplicate spots that were excluded from the data set. Overall, the variability associated with the slide making, spotting, and reading is considerably less than the variability between animals-even though these animals are housed and fed in highly controlled environments. Another important issue that must be addressed in studies applying this technology to changes in gene expression associated with xenobiotic exposure is related to the need to establish dose-response relationships. If the current studies had utilized a single dose of $\beta$-NF rather than a range of doses, incorrect conclusions might have been reached regarding up- or downregulation of metallothionein genes. Likewise, proper controls must include labeling with both Cy5 and Cy3 fluorescent dyes. For some genes, such as integrin alpha $\mathrm{V}$, which is a low copy number gene, dye labeling or reading bias yiel ded data suggesting that this gene was downregulated in response to all doses of $\beta$-NF. However, use of proper controls where samples from control animals were labeled with both dyes showed that the fluorescence intensity derived from Cy5 labeling of integrin alpha $\mathrm{V}$ was less than $40 \%$ of Cy3 fluorescence. Again, these data stress the need to label separate controls with both Cy3 and Cy5 dyes to establish a baseline for determining significant induction or repression of gene expression. Moreover, a clear delineation of the dose-response relationships is necessary for any study purporting to show changes in gene regulation in response to xenobiotic exposure.

In addition to the variability in the data obtained by microarray analysis, there are three other key questions that need to be addressed prior to using this approach as a semiquantitive tool for monitoring the levels of gene expression: (i) What is the dynamic range of the technique, which is related to the ability to measure differences in signal intensities over orders of magnitude? (ii) What is the the capability of this technique to measure small changes in gene expression? (iii) How well do the data obtained by Northern blot analysis correspond to the data obtained with microarrays?
The time course and magnitude of increase in Cyplal mRNA after treatment with $\beta$-naphthoflavone noted in the current studies are similar to those of studies completed several years ago in mice (13) and rats $(14,15)$. The maximal increase of mRNA for Cyplal occurred slightly later (12-24 h) than observed in the current studies ( $8 \mathrm{~h}$ ) but the magnitude of induction was similar to that noted in the data presented in Figs. 2 and 4. Nevertheless, coordinated assessment of both Cypla1 and Cypla2 by microarray and Northern blot analysis showed that the sensitivity (that is the ability to detect a statistically significant increase in signal over control) and dynamic range (i.e., the ability to detect increases in signal severalfold over control) was slightly better with the microarrays than with the Northern blots. Whereas a significant increase in signal intensity (Cy5/Cy3 fluorescence) was observed for Cypla2 at doses of $0.62 \mathrm{mg} / \mathrm{kg} \beta-\mathrm{NF}$, doses of $1.25 \mathrm{mg} / \mathrm{kg}$ were required to observe a statistically significant increase in the ratio of Cypla2/GAPDH by Northern blotting. Likewise, analysis of the increase in fluorescence ratios for both Cypla2 and Cypla1 associated with the highest doses of $\beta$-NF indicated a 12and 22-fold induction of these genes, respectively, while Northern blotting measurements for the same samples yielded apparent increases of 5- and 14-fold over control.

Our present work focuses on use of these arrays to detect environmental contamination. We are currently exploring the possibility that various toxicants (such as heavy metals, polychlorinated biphenyls, chlorinated ethylenes) will yield distinct fingerprints in terms of genes up- or downregulated in response to exposure. We also are utilizing subtractive hybridization approaches to identify additional ESTs that will help focus our current "toxicology chip" and this may aid in developing "chips" that are capable of discriminating between classes of toxic agents. A key question remains of whether the induction or repression of genes is sufficiently sensitive so that we will be able to detect changes at environmentally realistic exposure levels. Furthermore, the influence of diet, genetic heterogeneity, and environmental stressors will likely strongly influence mRNA levels in wildlife populations and thus variability of expression levels in unexposed populations could potentially mask changes associated with exposure to environmental toxicants unless these exposures are capable of producing large changes in mRNA levels.

\section{ACKN O WLEDGMENTS}

We thank Dr. Sharron Penn and Kate Bechtol (Molecular Dynamics) for careful review of the manuscript and Dr. David Rocke (UCD) for advice on data calculation. 


\section{REFERENCES}

1. DeRisi, J., Penland, L., Brown, P. O., Bittner, M. L., Meltzer, P. S., Ray, M., Chen, Y., Su, Y. A., and Trent, J . M. (1996) Nat. Genet. 14, 457- 460.

2. Heller, R. A., Schena, M., Chai, A., Shalon, D., Bedilion, T., Gilmore, J., Woolley, D. E., and Davis, R. W. (1997) Proc. Natl. Acad. Sci. USA 94, 2150-2155.

3. Schena, M., Heller, R. A., Theriault, T. P., Konrad, K., Lachenmeier, E., and Davis, R. W. (1998) Trends. Biotechnol. 16, 301306.

4. Shalon, D., Smith, S. J ., and Brown, P. O. (1996) Genome Res. 6, $639-645$.

5. Lashkari, D. A., DeRisi, J . L., McCusker, J . H., Namath, A. F., Gentile, C., Hwang, S. Y., Brown, P. O., and Davis, R. W. (1997) Proc. Natl. Acad. Sci. USA 94, 13057-13062.

6. Nuwaaysir, E., Bittner, M., Trent, J ., Barrett, J ., and Afshari, C. (1999) Mol. Carcinogen. 24, 153-159.

7. Medlin, J. (1999) Environ. Health Persp. 107, A256-A258.

8. Chen, J. R., Wu, P. C., Yang, J. Y., Huang, Y. P., Sher, M. H.,
Han, W. C., Kao, P. J ., Lee, T. F., Chiu, F., Chang, Y. W., Chu, C. W., Wu, R., and Peck, K. (1998) Genomics 51, 313-324.

9. Iyer, V. R., Eisen, M. B., Ross, D. T., Schuler, G., Moore, T., Lee, J. C. F., Trent, J. M., Staudt, L. M., Hudson, J ., Boguski, M. S., Lashkari, D., Shalon, D., Botstein, D., and Brown, P. O. (1999) Science 283, 83- 87.

10. Zhao, N., Hashida, N., Takahashi, Y., Misumi, Y., and Sakki, Y. (1995) Gene 156, 207-213.

11. Chomczynski, P., and Sacchi, N. (1987) Anal. Biochem. 162, 156-159.

12. Hanzel, D. K., Trojanowski, J . Q., J ohnston, R. F., and Loring, J . F. (1999) Nat. Biotechnol. 17, 53-57.

13. Miller, M. S., J ones, A. B., Chauhan, D. P., Park, S. S., and Anderson, L. M. (1989) Carcinogenesis 10, 875- 833.

14. Fagan, J ., Pastewka, J ., Chal berg, S., Gozukara, E., Guengerich, F., and Gelboin, H. (1986) Arch. Biochem. Biophys. 244, 261272.

15. Soderkvist, P., Poellinger, L., Toftgard, R., and Gustafsson, J -A. (1988) Cancer Res. 48, 3045-3049. 